\title{
Non-Syndromic Multiple Odontogenic Keratocysts: A Case Report and Comparison with Syndromic Multiple Odontogenic Keratocysts
}

\section{Someshwar Mahadeo Golgire, Aniruddha Annasaheb Varekar, Anil Patil", Shraddha Subhash Shetti and Dilip Magdum}

Department of Oral Pathology and Microbiology, Bharathi Vidyapeeth Deemed University Dental College and Hospital, Wanleswadi, Sangli, India

*Corresponding author: Anil Patil, Department of Oral Pathology and Microbiology, Bharathi Vidyapeeth Deemed University Dental College and Hospital, Wanleswadi, Sangli, India, Tel: +91 9850983500; E-mail: dranilp0888@gmail.com

Rec date: May 23, 2016; Acc date: June 25, 2016; Pub date: June 30, 2016

Copyright: ( $)$ 2016, Golgire SM, et al. This is an open-access article distributed under the terms of the Creative Commons Attribution License, which permits unrestricted use, distribution, and reproduction in any medium, provided the original author and source are credited.

\begin{abstract}
The Odontogenic Keratocyst (OKC) is a relatively common developmental odontogenic cyst arising from the dental lamina remnants. Multiple OKCs are rare and occur either in syndromic and non-syndromic groups. The Keratocyst demands special consideration because of its aggressive clinical nature and propensity for recurrence. Epithelial proliferation plays a significant role in behaviour of OKC and suggests that more aggressive behaviour is present in case of syndromic OKC than non-syndromic ones. Here we report a case of multiple OKCs in a 20 year old female patient having simultaneous occurrence of cystic lesions in maxilla and mandible without any syndromic manifestations. Comparison between syndromic and non syndromic multiple OKCs is also discussed.
\end{abstract}

Keywords: Odontogenic keratocyst; Gorlin goltz syndrome; Nonsyndromic; PTCH gene

\section{Introduction}

Odontogenic keratocyst (OKC) is derived from remnants of dental lamina, with a biologic behavior similar to neoplasm, with a distinctive lining of 6 to 10 cells in thickness and that exhibits a basal cell layer of palisaded cells and a surface of corrugated parakeratin [1]. OKC is the third most common cyst occurring in the oral cavity. OKC has potential to behave aggressively, can recur. In the latest WHO classification of odontogenic tumors in 2005, these lesions have been given the name "karatocystic odontogenic tumors" (KCOTs) [2]. It can be associated with the Nevoid basal cell carcinoma syndrome [3]. Multiple OKCs are rare and occur either in syndromic and nonsyndromic groups. The aggressive behavior of OKC might be expected to correlate with the proliferation of cyst epithelium. Epithelial proliferation plays a significant role in behavior of OKC and suggests that more aggressive behavior is present in case of syndromic cases than non-syndromic cases. Presentation with Multiple OKCs should be thoroughly scrutinized for categorizing in syndromic and nonsyndromic variety. Multiple KCOTs are mostly seen with Gorlin Goltz syndrome. However, though rarely, a few cases of non-syndromal multiple karatocystic odontogenic tumour have been reported in the literature [4]. This article reports a case of multiple OKCs in a nonsyndrome patient and highlight comparison with syndromic multiple OKCs and also a guideline to the general practitioners to know the importance of diagnosing the disease and enforcing a strict long-term follow-up whenever such a case is identified.

\section{Case Report}

A 20-year-old girl presented to the Department of Oral Medicine and Radiology with complaint of swelling and pus discharge in the lower posterior region of left side of jaw since the last one month (Figure 1).
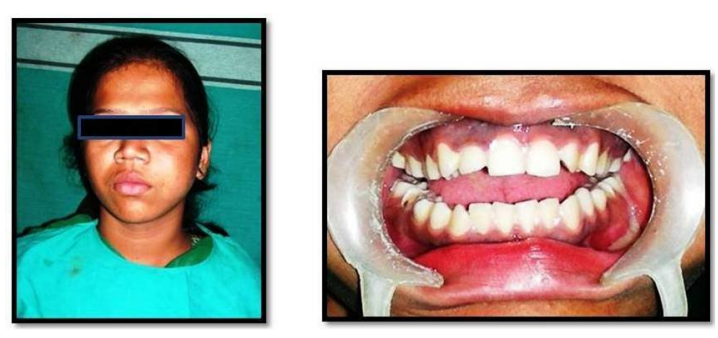

Figure 1: Clinical photographs.

There was no pain associated with it. Orthopantomogram (OPG) was advised which revealed multiple round to oval radiolucencies which were suggestive of multiple cystic lesions (Figure 2).

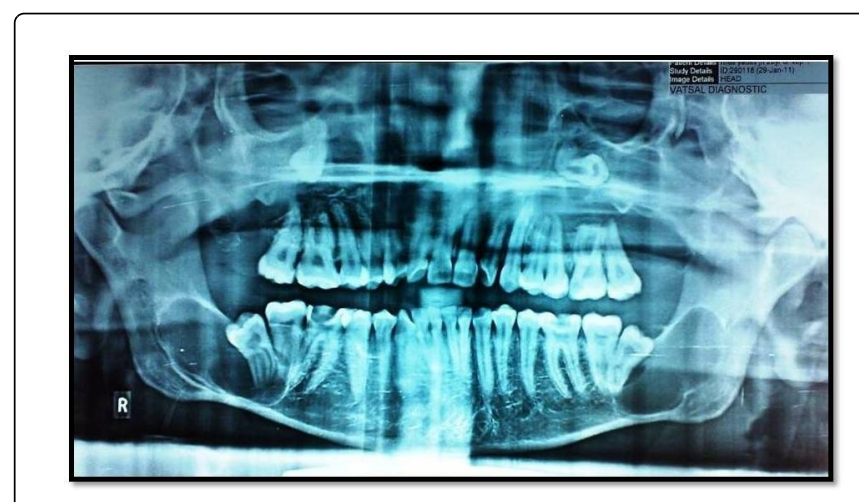

Figure 2: OPG showing all four cystic lesions.

The erupting left and right third molar tooth also had a cyst-like radiolucency over the crown. Thus, four cystic lesions (two in maxilla and two in mandible) were seen on OPG. Due to the presence of 
multiple cyst-like lesions in the jaws, patient was advised X-ray of skull and chest. No significant findings were seen on radiographs. The skin was devoid of any kind of lesions in the form of basal cell nevus, palmar or plantar pits. All the cystic lesions of the jaw were enucleated surgically (Figure 3).
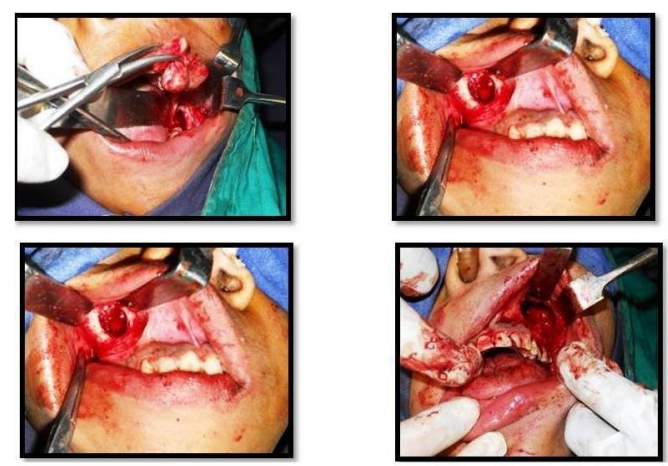

Figure 3: Surgical management of lesions.

The histopathologic examination of enucleated tissue was done. The cystic lining was made up of uniformly thick, stratified squamous epithelium of 5-6 layers thick, flat with corrugated parakeratin surface. The basal cell layer was cuboidal to columnar with well-polarized nuclei. Underlying connective tissue capsule was loose fibro cellular, with supporting vasculature, extravasated blood elements, strands, and nests of odontogenic epithelium. In all cysts, histopathologic features were suggestive of OKC (Figure 4).
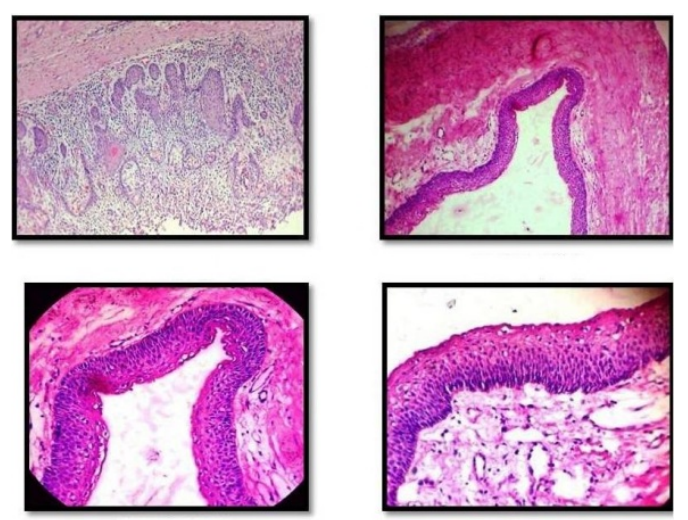

Figure 4: Histologically showing lining of parakeratinized OKC.

\section{Discussion}

OKC is a developmental odontogenic cyst, first described by Mikulicz and introduced by Philipsen in 1956, originating either from epithelial rests of the dental lamina or basal cell extensions from the overlying oral epithelium [4]. OKC is a common developmental odontogenic cyst and its biologic behaviour is similar to a benign neoplasm. Therefore, in the latest WHO classification of odontogenic tumors in 2005, it has been given the term karatocystic odontogenic tumor. KCOT may be found in any age with peak prevalence between second to third decades. The mandible to maxilla ratio is $2: 1$, with mandibular and ramus being the most common site. Small KCOTs are usually asymptomatic but larger ones may show clinical manifestations like pain, swelling or drainage. Our case, revealed only the swelling and discharge. Radiologically, KCOTs demonstrate a well-defined radiolucent area with smooth and often corticated margins and may be unilocular or multilocular. In $25 \%-40 \%$ of cases, an unerupted tooth is seen in association with the lesion. Microscopically shows characteristic features like a corrugated parakeratinized stratified Squamous epithelial lining with palisaded basal cell layer without rete ridge formation. In this case we revealed characteristic features of KCOT in histopathologic slides. Finally, the diagnosis of KCOT was established for all four cystic lesions [2].

In order to make a diagnosis of the Gorlin-Goltz syndrome, some diagnostic criteria have to be taken into account. The most important criteria to make a diagnosis for this syndrome are the presence of pigmented basal cell carcinomas, OKC, palmar and/or plantar pits, and ectopic calcifications of the falx cerebri [5-8]. Together with these major features, more than 100 minor features have been described. The more relevant are the following: cardiac or ovarian fibroma, macroencephaly, bifid ribs, kyphoscoliosis, cleft palate, medulloblastoma, alterations in the sella turcica, mandibular prognathia, lateral displacement of the inner canthus, frontal and biparietal bossing, imperfect segmentation of the cervical vertebrae, meningiomas, fibrosarcoma, rhabdomyosarcoma, short fourth metacarpal, ocular hypertelorism, congenital blindness, high arched eyebrows and palate, narrow sloping shoulders, immobile thumbs, low pitch voice in women, renal anomalies, and hypogonadism in men. In certain occasions, a tall height and even similar characteristics to acromegaly have been associated with the syndrome [9-12]. Evans et al. [13] first established major and minor criteria for the diagnosis of the syndrome and later were modified by Kimonis et al. [14]. The presence of two major and one minor or one major and three minor criteria are necessary to establish diagnosis [13-15].

\section{Major criteria [13-15]}

- Multiple basal cell carcinomas or one occuring under the age of 20 years.

- Histologically proven OKCs of the jaws.

- Palmar or plantar pits (three or more).

- Bilamellar calcifications of the falx cerebri.

- Bifid, fused, or markedly splayed ribs.

- First degree relative with nevoid basal cell carcinoma syndrome.

\section{Minor criteria [13-15]}

- Macrocephaly (adjusted for height).

- Congenital malformation: Cleft lip or cleft palate, frontal bossing, coarse face moderate or severe hypertelorism.

- Other skeletal abnormalities: Marked pectus deformity, marked syndactyly of the digits.

- Radiological abnormalities: Bulging of sella turcica, vertebral anomalies such as hemi vertebrae, fusion or elongation of vertebral bodies, modelling defects of the hands and feet, or flame-shaped hands or feet.

- Ovarian fibroma. 
Citation: Golgire SM, Varekar AA, Patil A, Shetti SS, Magdum D (2016) Non-Syndromic Multiple Odontogenic Keratocysts: A Case Report and Comparison with Syndromic Multiple Odontogenic Keratocysts. J Clin Case Rep 6: 818. doi:10.4172/2165-7920.1000818

Page 3 of 4

\section{- Medulloblastoma.}

Multiple KCOTs are usually considered as a component of GorlinGoltz syndrome or NBCCS, orofacial digital syndrome, Ehler- Danlos syndrome, Noonan syndrome or other syndromes. Rarely, multiple KCOTs are seen without other syndromic manifestations $[2,15]$.

Brannon reported that 5.8 percent of 312 cases of KCOTs had multiple cysts without any syndromic manifestations [16].

Parikh discussed a case of 19-year-old with two KCOTs in both jaws without any other syndromic features. Panoramic radiograph revealed two radiolucencies with corticated borders associated with impacted teeth [17].

Sholapurkur et al reported a case of 24 year-old with multiple nonsyndromic KCOTs in both jaws with chief complaint of a slow growing swelling since 3 years and drainage since 15 days. Lesions were cystlike radiolucencies associated with impacted teeth on panoramic radiograph [18].

Auluck et al. reported a case of 22 year-old patient with multiple recurrent KCOTs in all four quadrants with a complaint of pus drainage without pain or swelling. The patient had no any other manifestations associated with Gorlin Goltz Syndrome [19].
Guruprasad et al. reported a case 16-year-old patient with multiple KCOTs and a complaint of slow progressing swelling in both jaws without any characteristic features of syndrome [20].

Habibi et al. study on Iranian populations showed that $8.1 \%$ of 83 cases with KCOTs, were associated with NBCCS and 7.6\% of them had recurrence [21].

Bartake et al. reported a 20 - year-old case with multiple recurrent KCOTs without any other noticeable features indicative of Gorlin syndrome. No recurrence occurred after 3- year follow up. Syndrome is linked with mutation in the PTCH gene. Partial expression of the gene may result in occurrence of only non syndromic multiple recurring OKC [22].

The patient was followed up regularly for clinical and radiographic assessment after every 6 months and had shown no recurrence of cyst after 4 years of follow up.

Cases of syndromic and non syndromic multiple OKCs show differences in their clinical, microscopic, genetic and recurrence. The table shows comparison between syndromic and non syndromic multiple OKCs (Table 1).

\begin{tabular}{|c|c|c|c|c|c|}
\hline Sr. No & Characteristics & Our Case & Nonsyndromic OKC & Syndromic OKC & Reference \\
\hline 1 & Mean age group & 20 yrs & 40.4 years & $10-30$ years & Woolgar et al. 1987 a-c \\
\hline 2 & Gender predilection & Female & Male & Female & Woolgar et al. 1987 a-b \\
\hline 3 & Sites & $\begin{array}{l}\text { Two in maxilla and } \\
\text { two in mandible }\end{array}$ & Mandibular ramus area & Maxillary molar area & Woolgar et al. 1987 a-c \\
\hline 4 & Recurrence rate & $\begin{array}{l}\text { No recurrence till } \\
\text { date }\end{array}$ & $37 \%$ & $63 \%$ & $\begin{array}{l}\text { Vedtofte and pratorious (1997), } \\
\text { Forsell (1988), Asholfs et al. }\end{array}$ \\
\hline \multirow[t]{4}{*}{5} & \multicolumn{5}{|l|}{ Histopathology } \\
\hline & a) Epithelial lining & Thin & Thin & Thicker & \multirow{3}{*}{$\begin{array}{l}\text { Woolgar et al. } 1987 \text { a, } \\
\text { Ahlfors et al. } 1984, \\
\text { Myoung et al. } 2001\end{array}$} \\
\hline & b) Number of Mitotic figures & Less & Less & Increased & \\
\hline & c) Number of Satellite cysts & No & Less & Increased & \\
\hline \multirow[t]{5}{*}{6} & \multicolumn{5}{|l|}{ Immunohistochemistry } \\
\hline & a) Cytokeratin 17 & & + & ++ & \multirow{4}{*}{$\begin{array}{l}\text { Kimi et al. J Oral Maxillofac } \\
\text { Surg 2001; 58: 862-865. } \\
\text { Joshi et al. Dental Research } \\
\text { Journal, Jan 2012, Vol-9, Issue } \\
\text { 1, 100-106. }\end{array}$} \\
\hline & b) PCNA, Ki-67 and p53 & & + & ++ & \\
\hline & c) DNA positive cells & & + & ++ & \\
\hline & d) $\mathrm{Bcl} 2$ & & + & ++ & \\
\hline 7 & PTCH Expression & - & Less expression & More expression & $\begin{array}{l}\text { Auluck et al. Multiple } \\
\text { odontogenic } \\
\text { keratocysts: Report of a case. J } \\
\text { Can Dent Assoc 2006;72(7): } \\
651-6 .\end{array}$ \\
\hline
\end{tabular}

Table 1: Comparison between syndromic and non-syndromic OKCs.

\section{Conclusion}

Hereby we suggest that a detailed family history and thorough oral and skin examination should be performed for every suspected patient. In addition to these, Chest and skull radiographs, panoramic radiographs of the jaw and MRI and CT scan should be advised. As shown in various studies, syndromic cases have a female predominance. Hence suspected female patients should undergo Pelvic 
Citation: Golgire SM, Varekar AA, Patil A, Shetti SS, Magdum D (2016) Non-Syndromic Multiple Odontogenic Keratocysts: A Case Report and Comparison with Syndromic Multiple Odontogenic Keratocysts. J Clin Case Rep 6: 818. doi:10.4172/2165-7920.1000818

Page 4 of 4

ultrasonography. Due to high propensity of recurrence in OKC, it is mandatory to keep strict and long term follow up.

\section{References}

1. Shear M, Speight PM. Cyst of Oral and Maxillofacial Regions. (4thedn), Blackwell Publications.

2. Kargahi N, Kalantari M (2013) Non-syndromic multiple odontogenic keratocyst: a case report. J Dent (Shiraz) 14: 151-154.

3. Rajendran R. Shafer's- Text book of Oral Pathology. (6thedn.), Elsevier India.

4. Ozkan L, Aksoy S, Orhan K, Çetiner S, Uyaniket LO, et al. (2014) Case Report: Multiple keratocystic odontogenic tumour in a non- syndromal pediatric patient. Eur J Paediatr Dent 15: 2.

5. Ortega García de Amezaga A, García Arregui O, Zepeda Nuño S, Acha Sagredo A, Aguirre Urizar JM (2008) Gorlin-Goltz syndrome: clinicopathologic aspects. Med Oral Patol Oral Cir Bucal 13: 338-343.

6. Dixit S, Acharya S, Dixit PB (2009) Multiple odontogenic keratocysts associated with Gorlin-Goltz syndrome. Kathmandu Univ Med J (KUMJ) 7: 414-418.

7. Gnanam A, Rajkumar K, Krishnakumar Raja VB, Preeti T (2010) Odontogenic Keratocyst in nevoid basal cell carcinoma syndrome-A case report. SRM University Journal of Dental Sciences. 1:119-21.

8. Shear M (2002) The aggressive nature of the odontogenic keratocyst: is it a benign cystic neoplasm? Part 3. Immunocytochemistry of cytokeratin and other epithelial cell markers. Oral Oncol 38: 407-415.

9. Kalogeropoulou C, Zampakis P, Kazantzi S, Kraniotis P, Mastronikolis NS (2009) Gorlin-Goltz syndrome: incidental finding on routine ct scan following car accident. Cases J 2: 9087.

10. Sunil MK, Raghav Kumar, Guru EN, Vikash Ranjan (2010) Gorlin-Goltz syndrome. J Indian Acad Oral Med Radiol 22: 18-26.
11. Patil K, Mahima VG, Gupta B (2005) Gorlin syndrome: a case report. J Indian Soc Pedod Prev Dent 23: 198-203.

12. Rai S, Gauba K (2007) Jaw cyst-Basal cell nevus-Bifid rib syndrome: a case report. J Indian Soc Pedod Prev Dent 25: 137-139.

13. Evans DG, Ladusans EJ, Rimmer S, Burnell LD, Thakker N, et al. (1993) Complications of the naevoid basal cell carcinoma syndrome: results of a population based study. J Med Genet 30: 460-464

14. Kimonis VE, Mehta SG, Digiovanna JJ, Bale SJ, Pastakia B (2004) Radiological features in 82 patients with nevoid basal cell carcinoma (NBCC or Gorlin) syndrome. Genet Med 6: 495-502.

15. Joshi PS, Deshmukh V, Golgire S (2012) Gorlin-Goltz syndrome. Dent Res J (Isfahan) 9: 100-106.

16. Brannon RB (1976) The odontogenic keratocyst. A clinicopathologic study of 312 cases. Part I. Clinical features. Oral Surg Oral Med Oral Pathol 42: 54-72.

17. Parikh NR (2010) Non-syndromic multiple odontogenic Keratocyst Report of case. J Advanc Dent Res 1: 71-74.

18. Sholapurkar AA, Varn RM, Pai KM, Geetha V (2008) Non- Syndromic Multiple Odontogenic Keratocysts: report of case. Rev Clín Pesq Odontol 4: 193-199.

19. Auluck A, Suhas S, Pai KM (2006) Multiple odontogenic keratocysts: report of a case. J Can Dent Assoc 72: 651-656.

20. Guruprasad Y, Chauhan DS (2012) Multiple odontogenic Keratocyst in a nonsyndromic patient. Journal of Cranio- Maxillary Diseases 1: 36-40.

21. Habibi A, Saghravanian N, Habibi M, Mellati E, Habibi M (2007) Keratocystic odontogenic tumor: a 10-year retrospective study of 83 cases in an Iranian population. J Oral Sci 49: 229-235.

22. Bartake A, Shreekanth N, Prabhu S, Gopalkrishnan K (2011) Nonsyndromic recurrent multiple odontogenic keratocysts: a case report. J Dent (Tehran) 8: 96-100. 